\title{
Comparative Clinical Evaluation of Two Local Drug Delivery Agents (Neem Chip and Turmeric Chip) in Chronic Periodontitis: An Experimental Study
}

\author{
Komal Saini ${ }^{1}$, Priyanka Chopra $^{2}$, Amit Bhardwaj $^{3}$, Manish Yadav ${ }^{4}$, Sachin Saini $^{5}$
}

\begin{abstract}
Aim and objective: This study aimed to evaluate the efficacy of herbal local drug delivery (LDD) agents as an adjunct to scaling and root planing (SRP) and SRP alone in the treatment of chronic periodontitis.

Material and methods: This split-mouth study was conducted at the Department of Periodontology, SGT Dental College, Haryana, in 30 patients between 30 years and 65 years of age where 90 sites ( 3 sites in one patient) were selected. Only those teeth with probing pocket depth (PPD) of $\geq 5 \mathrm{~mm}$ were included. Sites were randomized into three treatment groups. Group I with SRP + neem chip, group II with SRP + turmeric chip, and group III received SRP only. Clinical parameters plaque index (PI), gingival index (GI), PPD, and relative attachment level (RAL) were recorded at baseline, 1 month after the intervention, and at 3 months. Intergroup comparisons were done using Kruskal-Wallis test followed by post hoc comparison using Mann-Whitney $U$ test.

Results: Mean PI and GI at 1 month for group I, II, and III were $(1.33 \pm 0.28,1.37 \pm 0.28$, and $1.66 \pm 0.27)(1.20 \pm 0.31,1.24 \pm 0.26$, and $1.31 \pm$ $0.39)$, respectively. Improvement in mean PI and mean GI of group I and group II at 1 month is significant when compared with group III ( $p<$ 0.05). Probing pocket depth at 1 month for group I, II, and III was $4.16 \pm 0.88,4.21 \pm 0.61$, and $4.63 \pm 0.68$, respectively ( $p<0.05$ for all groups). Mean RAL at 1 month for group I, II, and III was $8.41 \pm 1.59,8.43 \pm 1.66$, and $9.01 \pm 1.50$, respectively. The mean RAL of group I and group II is significant when compared with group III at 1 month $(p<0.05)$.

Conclusion: Better immediate results can be achieved in the management of chronic periodontitis by the use of locally delivered neem and turmeric extract in form of chips.

Clinical significance: These herbal chips are natural, cost-effective without any side effects, and can be used in treating chronic periodontitis. Keywords: Chronic periodontitis, Curcumin, Local drug delivery, Neem chip, Turmeric chip.

World Journal of Dentistry (2021): 10.5005/jp-journals-10015-1818
\end{abstract}

\section{INTRODUCTION}

Chronic periodontitis is an inflammatory condition of the supporting tissues of the teeth caused primarily by mixed microbial infection. ${ }^{1}$ This complex inflammatory process results in loss of periodontal tissue attachment and alveolar bone resulting in periodontal pocket formation. The ultimate goal of all periodontal therapy is to restore the health of inflamed tissue, eliminate the diseased pockets, and reduce the number of pathogenic microorganisms. ${ }^{2}$ Thus, surgical and nonsurgical treatment modalities for removing plaque biofilm are essential for the management of chronic periodontitis. ${ }^{3}$

Scaling and root planing (SRP) procedures have been used as the "gold standard" for nonsurgical mechanical therapy. ${ }^{4}$ This conventional therapeutic module effectively decreases the microbial load, but recolonization of the same cannot be prevented. ${ }^{5}$ Systemic antibiotics are often used as an adjuvant to this treatment. To avoid the undesired effect of systemic antibiotics, Goodson gives the concept of controlled drug delivery for treatment of chronic periodontitis and observed that 100-fold higher concentrations of the drug can be attained through the local route as compared to systemic drug regimen without side effects. This helps to avoid the development of drug resistance at nonoral body sites. ${ }^{6,7}$

Various antimicrobial agents such as tetracycline, 10\% doxycycline, $2 \%$ minocycline, metronidazole, and chlorhexidine (CHX) gluconate have been used and investigated as local drug delivery (LDD) in the treatment of periodontal diseases. ${ }^{8}$ In today's
${ }^{1}$ P60/D Shankar Vihar, New Delhi, India

2,3 Department of Periodontics, Faculty of Dental Sciences, SGT University, Gurugram, Haryana, India

${ }^{4}$ Department of Pharmaceutics, SGT College of Pharmacy, SGT University, Gurugram, Haryana, India

${ }^{5}$ ENT Department, Army College of Medical Sciences, New Delhi, India Corresponding Author: Komal Saini, P60/D Shankar Vihar, New Delhi, India, Phone: +91 9319712233, e-mail: komalbrs1@gmail.com

How to cite this article: Saini K, Chopra P, Bhardwaj A, et al. Comparative Clinical Evaluation of Two Local Drug Delivery Agents (Neem Chip and Turmeric Chip) in Chronic Periodontitis: An Experimental Study. World J Dent 2021;12(2):138-143.

Source of support: Nil

Conflict of interest: None

era, research is being focused mainly on the use of natural products as LDD agents. There have been various formulations under study which increased our curiosity about the medicinal value of natural products such as turmeric, aloe vera, neem, tulsi, cocoa husk, and pomegranate, and these all are tested widely these days. ${ }^{9}$

Neem and turmeric have a unique anti-inflammatory property. The advantage that these herbal plants can be fabricated into chips and delivered at the local site goes a long way in the management of the local inflammatory process. Easy application of these chips 
and no side effects of herbal products leads to our thinking of utilizing them in chronic periodontitis treatment. Hence, in this study, we intend to evaluate the efficacy of these herbal chips as LDD agents adjuvant to SRP vs SRP alone in the treatment of chronic periodontitis.

\section{Materials and Methods \\ Study Sample and Selection Criteria}

This study was conducted in the Department of Periodontology, SGT Dental College, Gurugram, Haryana, from April 2018 to January 2019. A total number of 90 sites were selected in 30 patients with chronic periodontitis with no other comorbidity the selected patients were between 30 and 65 years of age and with $\geq 20$ teeth in the mouth. Three test sites from any three quadrants of mouth were selected randomly in each patient. Only those teeth with probing pocket depth (PPD) of $\geq 5 \mathrm{~mm}$ were included. Smokers, tobacco chewers, and those with a history of allergy or previous dental surgery or previous treatment with antibiotics in the last 3 months were excluded. The study was approved by Institutional ethical committee No. SGTU/FDS/MDS/24/1/672 dt 21/12/2017. All the patients were well informed and written informed consent was taken.

\section{Study Design}

This study is a split-mouth experimental study of 3-month duration. The study design is explained in detail in Flowchart 1. All the procedures were done by a single investigator (KS). plaque index (PI) and gingival index (GI) were measured and recorded as baseline data. ${ }^{10,11}$ Probing pocket depth measured using a graduated periodontal probe (PCP UNC-15, Hu-Friedy ${ }^{\circledR}$ Manufacturing Co., Chicago, IL, USA) by inserting the probe into the gingival sulcus, and readings were taken from the gingival margin till the base of the pocket. Alginate impressions were made to prepare customized acrylic stents that would act as a reference guide for recording PPD and relative attachment levels (RALs) at the experimental sites. All measurements at baseline, 1 month, and 3 months were done by an investigator (PC).

The study samples were stratified randomly into three groups with a stratified random sampling method:

Group I: Sites to be treated with neem chip in addition to SRP.

Group II: Sites to be treated with turmeric chip in addition to SRP. Group III: Sites treated with the only SRP in addition to a placebo chip.

Group I and II were experimental groups and group III was a control group. Blinding was done by ensuring that the investigator involved in measurement was unaware of site allocations.

\section{Preparation and Composition of Chips}

Neem and turmeric chips used in the study were indigenously prepared in the laboratory in Guru Nanak Institute of Pharmacy, Ibrahimpatnam, Hyderabad. The chip was customized so that it measures $4 \times 2 \mathrm{~mm}$ with a thickness of $0.3 \mathrm{~mm}$ and its weight was restricted to $10 \mathrm{mg}$ in a biodegradable hydroxypropyl cellulose (HPC) matrix. Each chip was customized so that it will contain neem/turmeric 5\%, HPC-1000 mg, poly vinylpyrrolidone-100 mg, poly ethylene glycol-100 mg, and ethanol/water-10 mL by weight. Neem chips were green in color and turmeric chips were yellow, respectively (Figs $1 \mathrm{~A}$ and $\mathrm{B}$ ). The placebo chip also measures $4 \times$ $2 \mathrm{~mm}$ with a thickness of $0.3 \mathrm{~mm}$ and its weight was restricted to $10 \mathrm{mg}$ in a biodegradable HPC matrix. Placebo chips did not contain any active ingredient. They were transparent as shown in Figure 1C. All chips were sterilized by gamma radiations and packed individually.

Flowchart 1: Study design

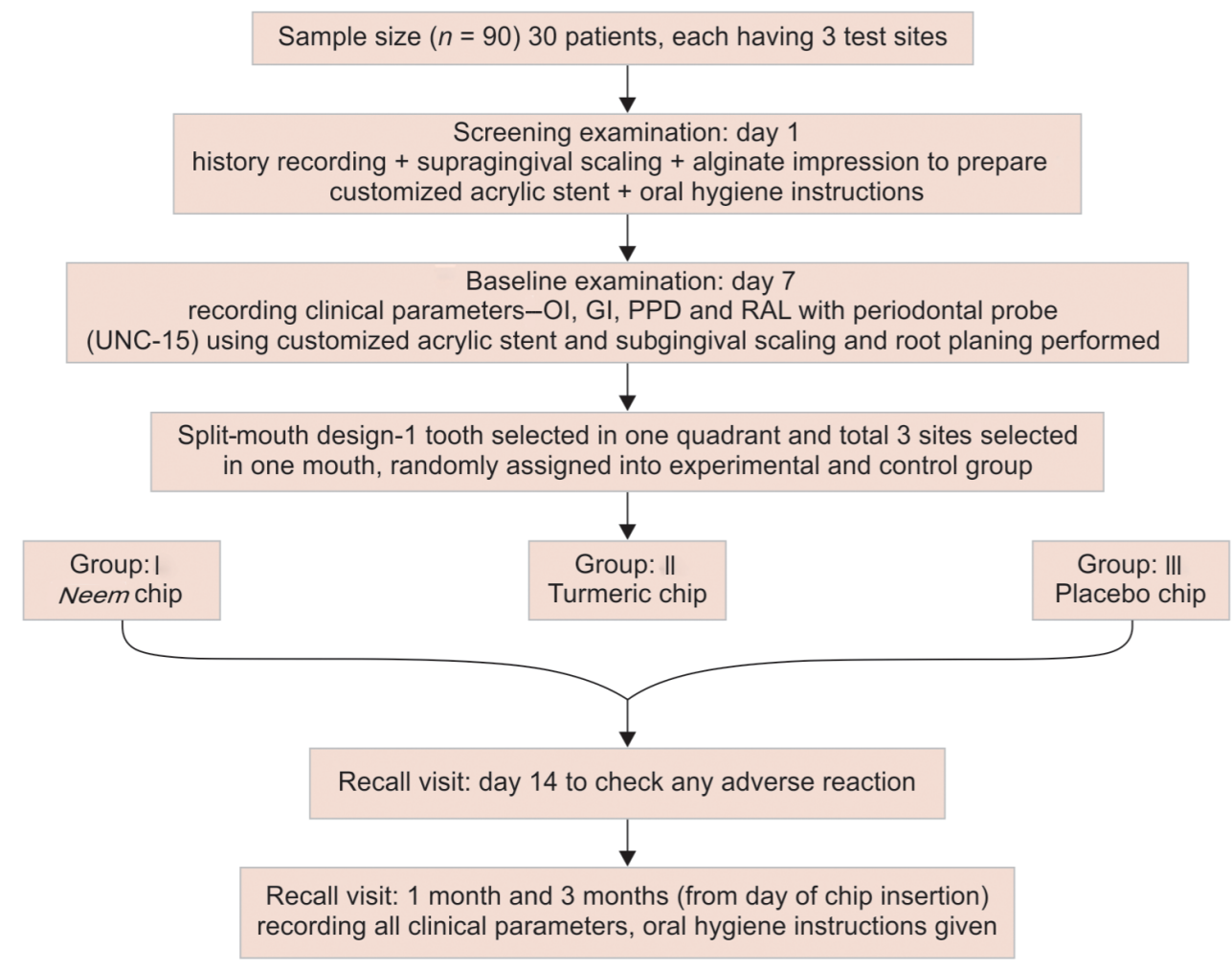



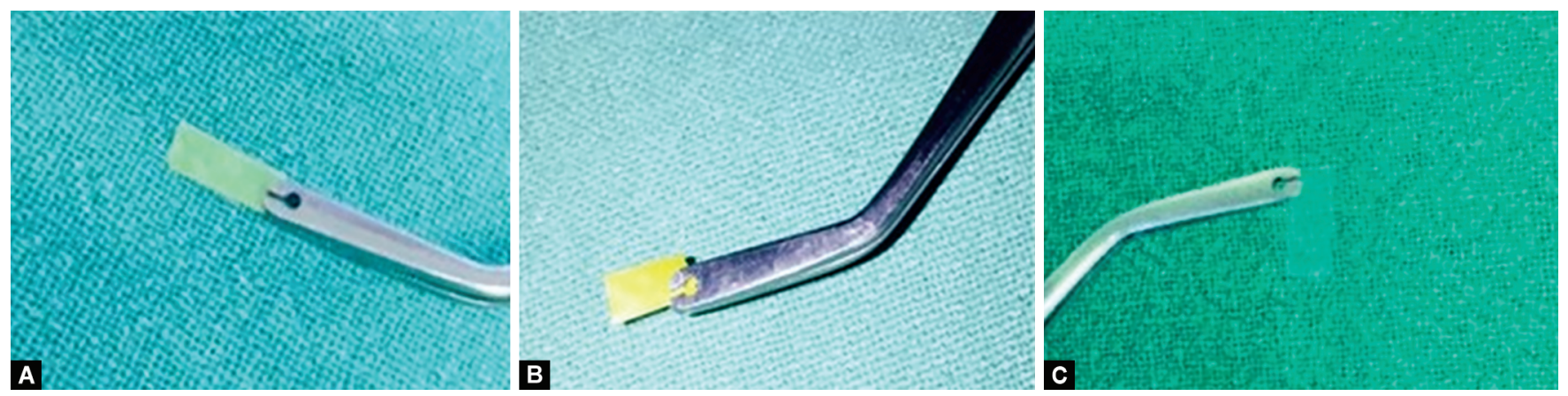

Figs 1 A to C: (A) Neem chip; (B) Turmeric chip; (C) Placebo chip

Table 1: Intergroup comparison of plaque index score. Plaque index scores for three groups are given at baseline, 1 month, and 3 months

\begin{tabular}{|c|c|c|c|c|c|c|}
\hline \multicolumn{2}{|c|}{ Plaque index scores } & \multirow{2}{*}{$\frac{\text { Mean }}{1.9597}$} & \multirow{2}{*}{$\begin{array}{l}\text { Std. deviation } \\
0.37135\end{array}$} & \multirow{2}{*}{$\begin{array}{l}\text { Std. error } \\
0.06670\end{array}$} & \multirow{2}{*}{$\begin{array}{l}p \text { value } \\
0.776\end{array}$} & \multirow{2}{*}{$\begin{array}{l}\text { Post hoc pairwise } \\
\text { comparison } \\
-\end{array}$} \\
\hline At baseline & Group I & & & & & \\
\hline & Group II & 1.9516 & 0.34411 & 0.06180 & & \\
\hline & Group III & 2.0403 & 0.32975 & 0.05923 & & \\
\hline \multirow[t]{3}{*}{ At 1 month } & Group I & 1.3306 & 0.28422 & 0.05105 & $0.04^{*}, 0.03^{*}$ & $A-C^{*}, B-C^{*}$ \\
\hline & Group II & 1.3710 & 0.28041 & 0.05036 & & \\
\hline & Group III & 1.6677 & 0.27189 & 0.04883 & & \\
\hline \multirow[t]{3}{*}{ At 3 months } & Group I & 1.2984 & 0.29874 & 0.05366 & 0.045 & \\
\hline & Group II & 1.3710 & 0.29489 & 0.05296 & & \\
\hline & Group III & 1.4435 & 0.30076 & 0.05402 & & \\
\hline
\end{tabular}

*Comparatively significant

\section{Procedure}

After SRP at the selected target sites with periodontal PPD $\geq 5 \mathrm{~mm}$, subsequently deepest pocket in the quadrant was selected. Both hand and ultrasonic scaling methods were used for SRP. Before inserting the chip, the area was dried with the cotton rolls. A sterile pack of the individual chip was opened. The flat end of the chip was grasped with a tweezer and the rounded end of the chip was pressed apically into the test site so that the chip rests subgingivally at the base of the pocket and making sure that it is not exposed. After that periodontal dressing (Coe-pak) was placed to prevent the dislodgment of the chip.

The patients were then instructed to continue with regular oral hygiene measures, after treatment except for the use of any chemotherapeutic mouth rinses and oral irrigation devices. Patients were also advised not to do flossing for at least 10 days to avoid any possibility of dislodging the chips. All patients were recalled after 7 days for pack removal and evaluated for any adverse clinical signs. Patients were then recalled at 01 month after insertion of chip and all clinical parameters (PI, GI, PPD, and RAL) were recorded. Oral hygiene instructions were further reinforced. Patients were then again recalled after 2 months to record all clinical parameters (PI, GI, PPD, and RAL) for 03 months. No adverse effect was seen in any patient.

\section{Statistical Analysis}

All data were entered into a Microsoft Excel spreadsheet by an investigator ( $A B)$ and was checked for any discrepancies. Summarized data were presented using tables and graphs. The data were analyzed by SPSS (21.0 version). Shapiro-Wilk test was used to check which all variables were following a normal distribution. Data were not normally distributed ( $p$ value was $<0.05)$. Therefore, bivariate analyzes were performed using the nonparametric tests, i.e., Mann-Whitney $U$ (for comparing two independent groups), Wilcoxon sum rank test for comparing two dependent means, and Kruskal-Wallis test (for comparing more than two groups).

\section{Results}

Mean PI at 1 month for group I, II, and III was $1.33 \pm 0.28,1.37 \pm 0.28$, and $1.66 \pm 0.27$, respectively. Improvement in mean PI of group I and group II is significant when compared with group III $(p<0.05)$. At 3 months, the mean PI was $1.29 \pm 0.29,1.37 \pm 0.29$, and $1.44 \pm$ 0.30 for group I, II, and III, respectively. Improvement in mean PI from 1 to 3 months is not significant in any group $(p>0.05)$. This PI score for three test groups at baseline, 1 month, and 3 months is shown in Table 1.

Intergroup comparison showed no significant difference in $\mathrm{Gl}$ at baseline. Mean GI at 1 month for group I, II, and III was 1.20 $\pm 0.31,1.24 \pm 0.26$, and $1.31 \pm 0.39$, respectively. Improvement in $\mathrm{Gl}$ is significant in all groups at one month $(p<0.05)$. At 3 months, mean GI was $1.29 \pm 0.28,1.37 \pm 0.29$, and $1.39 \pm 0.35$ for group I, II, and III, respectively. Improvement in mean $\mathrm{Gl}$ of both group I and group II at 1 month is significant when compared with group III $(p<0.05)$. This $\mathrm{Gl}$ score for three test groups at baseline, 1 month, and 3 months is shown in Table 2

Probing pocket depth at 1 month for group I, II, and III was $4.16 \pm 0.88,4.21 \pm 0.61$, and $4.63 \pm 0.68$, respectively $(p<0.05$ for 
Table 2: Intergroup comparison of gingival index score for three groups are given at baseline, 1 month, and 3 months

\begin{tabular}{|c|c|c|c|c|c|c|}
\hline \multicolumn{2}{|c|}{ Gingival index score } & \multirow{2}{*}{$\frac{\text { Mean }}{1.9355}$} & \multirow{2}{*}{$\begin{array}{l}\text { Std. deviation } \\
0.37621\end{array}$} & \multirow{2}{*}{$\begin{array}{l}\text { Std.error } \\
0.06757\end{array}$} & \multirow{2}{*}{$\begin{array}{l}p \text { value } \\
<0.070\end{array}$} & \multirow{2}{*}{$\begin{array}{l}\text { Post hoc pairwise } \\
\text { comparison } \\
-\end{array}$} \\
\hline At baseline & Group I & & & & & \\
\hline & Group II & 1.9355 & 0.30254 & 0.05434 & & \\
\hline & Group III & 2.0726 & 0.33661 & 0.06046 & & \\
\hline \multirow[t]{3}{*}{ At 1 month } & Group I & 1.2016 & 0.31238 & 0.05610 & $0.034^{*}, 0.024^{*}$ & $A-C^{*}, B-C^{*}$ \\
\hline & Group II & 1.2419 & 0.26991 & 0.04848 & & \\
\hline & Group III & 1.3145 & 0.39774 & 0.07144 & & \\
\hline \multirow[t]{3}{*}{ At 3 months } & Group I & 1.2961 & 0.27337 & 0.04910 & $>0.05$ & \\
\hline & Group II & 1.3790 & 0.28774 & 0.05168 & & \\
\hline & Group III & 1.3952 & 0.35809 & 0.06431 & & \\
\hline
\end{tabular}

${ }^{*}$ Comparatively significant

Table 3: Intergroup comparison of probing pocket depth for three groups is given at baseline, 1 month, and 3 months

\begin{tabular}{|c|c|c|c|c|c|c|}
\hline \multicolumn{2}{|c|}{ Probing pocket depth } & \multirow{2}{*}{$\frac{\text { Mean }}{5.435}$} & \multirow{2}{*}{$\begin{array}{l}\text { Std. deviation } \\
0.761\end{array}$} & \multirow{2}{*}{$\begin{array}{l}\text { Std. error } \\
0.137\end{array}$} & \multirow{2}{*}{$\begin{array}{l}p \text { value } \\
0.320\end{array}$} & \multirow{2}{*}{$\begin{array}{l}\text { Post hoc pairwise } \\
\text { comparison } \\
-\end{array}$} \\
\hline At baseline & Group I & & & & & \\
\hline & Group II & 5.431 & 0.597 & 0.107 & & \\
\hline & Group III & 5.419 & 0.660 & 0.118 & & \\
\hline \multirow[t]{3}{*}{ At 1 month } & Group I & 4.161 & 0.8887 & 0.1596 & $0.020^{*}, 0.026^{*}$ & $A-C^{*}, B-C^{*}$ \\
\hline & Group II & 4.210 & 0.6161 & 0.1107 & & \\
\hline & Group III & 4.632 & 0.6823 & 0.1226 & & \\
\hline \multirow[t]{3}{*}{ At 3 months } & Group I & 3.919 & 0.8573 & 0.1540 & 0.064 & \\
\hline & Group II & 4.181 & 0.6843 & 0.1229 & & \\
\hline & Group III & 4.323 & 0.6525 & 0.1172 & & \\
\hline
\end{tabular}

${ }^{*}$ Comparatively significant

Table 4: Intergroup comparison of relative attachment level for three groups is given at baseline, 1 month, and 3 months

\begin{tabular}{|c|c|c|c|c|c|c|}
\hline \multicolumn{2}{|c|}{ Relative attachment level } & \multirow{2}{*}{$\begin{array}{l}\text { Mean } \\
9.742\end{array}$} & \multirow{2}{*}{$\begin{array}{l}\text { Std. deviation } \\
1.5910\end{array}$} & \multirow{2}{*}{$\begin{array}{l}\text { Std. error } \\
0.2857\end{array}$} & \multirow{2}{*}{$\begin{array}{l}p \text { value } \\
0.070\end{array}$} & \multirow{2}{*}{$\begin{array}{l}\text { Post hoc pairwise } \\
\text { comparison } \\
-\end{array}$} \\
\hline At baseline & Group I & & & & & \\
\hline & Group II & 9.629 & 1.6123 & 0.2896 & & \\
\hline & Group III & 9.935 & 1.4591 & 0.2621 & & \\
\hline \multirow[t]{3}{*}{ At 1 month } & Group I & 8.419 & 1.5389 & 0.2764 & 0.024 & $A-C^{*}, B-C^{*}$ \\
\hline & Group II & 8.435 & 1.6620 & 0.2985 & & \\
\hline & Group III & 9.016 & 1.5027 & 0.2699 & & \\
\hline \multirow[t]{3}{*}{ At 3 months } & Group I & 8.261 & 1.5351 & 0.2757 & 0.423 & - \\
\hline & Group II & 8.371 & 1.6831 & 0.3023 & & \\
\hline & Group III & 8.842 & 1.6677 & 0.2995 & & \\
\hline
\end{tabular}

*Comparatively significant

all groups). At 3 months for group I, II, and III was $3.91 \pm 0.85,4.18$ \pm 0.69 , and $4.32 \pm 0.62$, respectively. Improvement in mean PPD of group I and group II is significant when compared with group III $(p<0.05)$. However, improvement in mean PPD of group I and II in comparison to group III is not statistically significant at 3-month follow-up $(p>0.05)$ as shown in Table 3.

Relative attachment level at 1 month for group I, II, and III was $8.41 \pm 1.59,8.43 \pm 1.66$, and $9.01 \pm 1.50$, respectively. At 3 months for group I, II, and III was $8.26 \pm 0.27,8.37 \pm 0.3$, and 8.74 \pm 0.29 , respectively. Improvement in mean RAL of group I and group II is significant when compared with group III $(p<0.05)$ at 1 month. However, improvement in mean RAL of both test groups in comparison to group III is statistically insignificant at 3-month follow-up $(p>0.05)$ as shown in Table 4.

\section{Discussion}

Since the prime etiological factor is plaque formation, so till date the goal of periodontal therapy is aimed at removing supra- and subgingival plaque biofilm by mechanical debridement, keeping this context in mind study is planned to compare control group SRP along with placebo chip (Hawthorne effect) to herbal LDD agents adjunct to SRP.

Local drug delivery agents directly act on periopathogens residing in periodontal pockets and aids in controlling the disease. They are available as a gel, strips, nanosphere, microspheres, chips, etc. The various locally delivered antimicrobials agents available are listed below:

- Tetracycline fibers.

- Metronidazole gel. 
- Minocycline ointment.

- Chlorhexidine chips.

- Doxycycline hyclate in a resorbable polymer.

- Resorbable tetracycline in fibrillar collagen.

- Minocycline microspheres.

- Azithromycin gel, etc. ${ }^{12}$

Oral rinses and irrigating devices are easy to use and commonly employed but irrigation system is not much successful in managing periodontitis as the desired concentration of a drug is not achieved in the pocket, as well as there is inadequate penetration of drug in the deep pocket. ${ }^{13}$

In the present study, we have used antimicrobial agents in form of biodegradable chips as this route provides more sustainability for the drug. One of the commercially available FDA-approved LDD agents containing $0.02 \%$ chlorhexidine (Periochip) is considered as the gold standard by some authors in the treatment of periodontitis. ${ }^{14,15}$ The disadvantage is that they are expensive, so we used indigenously produced biodegradable chips that were cost-effective.

We have used neem (Azadirachta indica) and turmeric (Curcumin longa) in the treatment of periodontitis because of their antiinflammatory, antimicrobial, antioxidant, immunostimulant, and anticancer properties. Turmeric is an easily available, renewable resource, and cost-effective, so used in various inflammatory diseases including chronic periodontitis as a LDD agent. ${ }^{16}$ Curcumin acts as an anti-inflammatory agent by down-regulating the activity of cyclooxygenase-2 (COX-2), lipoxygenase, and inducible nitric oxide synthase (iNOS) enzymes. ${ }^{17}$

Neem twigs are in use since ancient times for cleaning teeth and gum massage. The antibacterial activity of neem against periodontal pathogens has been proven in various studies. Rao et al. have proved the efficacy of neem in reducing plaque cultures and gram-negative bacteria as compared to the other denitrifies which are available commercially. ${ }^{18}$ Studies done by Chaterjee et al. and Chaudhary et al. showed that mouth rinse prepared from leaf extract is highly efficacious in controlling gingivitis. ${ }^{19,20}$

It is seen that the effect of the locally delivered controlledrelease drug is evident up to 11 weeks after administration. Hence, planned our follow-up at 1-month and 3-month interval. ${ }^{21}$

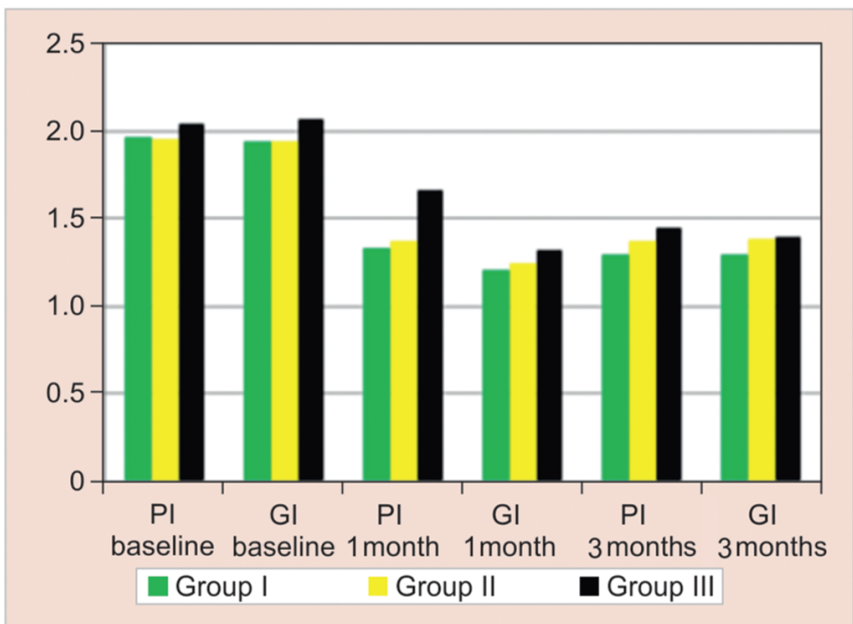

Fig. 2: Comparison of $\mathrm{PI}, \mathrm{Gl}$ at baseline, 1 month, and 3 months in group $\mathrm{I}$, II, and III. *PI, plaque index; Gl, gingival index
In the present study, we have used Neem and Turmeric because these two products are well known among our study population and also easily acceptable. Moreover, both Neem and turmeric chips were available commercially, cost-effective, and can be stored at room temperature. On comparison of neem chip and turmeric chip as an adjunct to SRP vs SRP alone in microbial plaque accumulation (PI) from baseline to 1 month and 3 months by using Silness and Loe, PI we found that after 1-month follow-up group I and II with neem and turmeric were more efficient than group III in reducing plaque. Results can be attributed due to the additional antibacterial properties of these LDD agents. Contrary to the results of our study, Singh et al. stated that no significant difference in PI from baseline to 1 month was seen while comparing curcumin chip as an adjunct to scaling and root planing. ${ }^{22}$ Similar to our results, study done by Vennila et al. in 2016 showed that plaque accumulation decreases significantly on day 7 and $21 .{ }^{13}$ At 3 months, no difference in plaque accumulation among the test and control group.

In our study, changes in Gl showed a significant reduction at 1 month. At 3 months, there is a slight increase in gingival scores that can be attributed due to noncompliance to oral hygiene instructions. Comparison of $\mathrm{Pl}$ and $\mathrm{Gl}$ of all three groups represented in Figure 2. Gottumukkala et al. showed that curcumin gel and chlorhexidine were better in reducing the gingival inflammation at 1 month but at 3 months chlorhexidine group was better as there was a recurrence of inflammation in the curcumin group. Contrary to our results, Singh et al. showed after a 1-month interval GI have no significant difference in all three groups Periochip + SRP, curcumin chip + SRP, and SRP. ${ }^{23,24}$

Both the test groups showed a decrease in PPD and RAL from baseline to 1 month significantly as compared to the control group. Jain et al. in a similar study compared the neem chip + SRP with SRP alone and the results were in favor of our study at 6 weeks. ${ }^{24}$ Contrary to our results, Mehta et al. in 2015 used neem extract as an LDD agent and found it to be marginally better than SRP but not significant. ${ }^{25}$ Comparison of PPD and RAL at baseline 1 month and 3 months is shown in Figure 3.

Both agents neem and turmeric chip were found to be effective in reducing clinical parameters such as $\mathrm{PI}, \mathrm{GI}, \mathrm{PPD}$, and RAL.

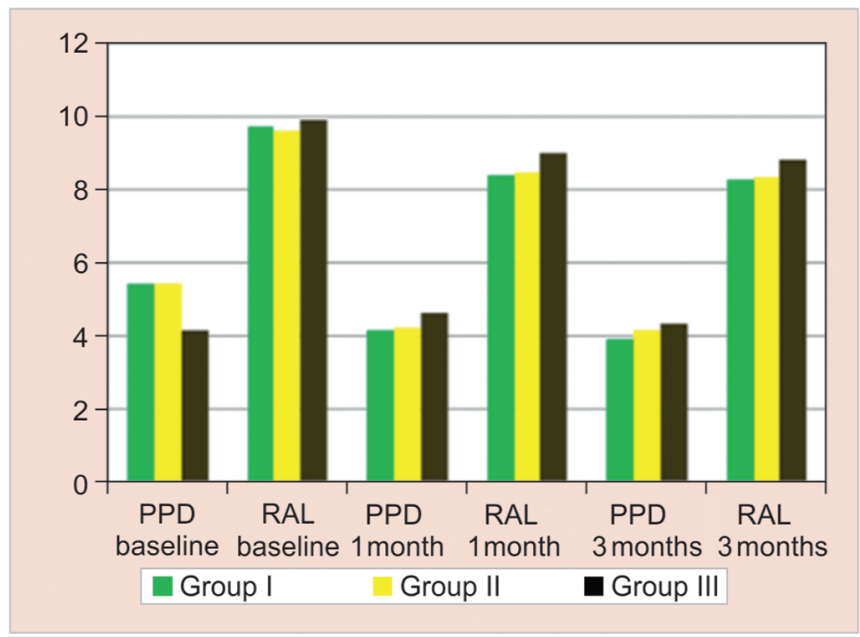

Fig. 3: Comparison of PPD, RAL at baseline, 1 month, and 3 months in group I, II, and III. *PPD, probing pocket depth; RAL, relative attachment level 


\section{Conclusion}

Neem and turmeric as LDD agents adjunct to SRP are more effective in controlling chronic periodontitis as compared to SRP alone in a short duration of 1 month. However, the long-term effects of these agents are still debatable. Further studies with large sample size, long-term follow-ups, and microbiological culturing for evaluating the specific bacterial inhibitory effects of indigenously produced herbal chips are required.

\section{Clinical Significance}

These herbal substitutes, i.e., neem chip and turmeric chip are natural products free from side effects and cost-effective LDD agent in managing chronic periodontitis.

\section{Acknowledgments}

We would like to thank Dr Sreenivasan, Principal Guru Nanak Institute of Pharmacy, Ibrahimpatnam, Hyderabad, for helping in herbal chip fabrication.

\section{References}

1. Philstrom BL, Michalowicz BS, Johnson NW. Periodontal disease. Lancet 2005;366(9499):1809-1820. DOI: 10.1016/S0140-6736(05)67728-8.

2. Berglundh T, Donati $M$. Aspects of adaptive host response in periodontitis. J Clin Periodontol 2005;32(s6):87-107. DOI: 10.1111/j.1600-051X.2005.00820.x.

3. Baker KA. The role of dental professionals and the patient in plaque control. Periodontol 2000 1995;8(1):108-113. DOI: 10.1111/j.16000757.1995.tb00048.x.

4. Cugini MA, Haffajee AD, Smith C, et al. The effect of scaling and root planing on the clinical and microbiological parameters of periodontal diseases: 12 months results. J Clin Periodontol 2000;27(1):30-36. DOI: 10.1034/j.1600-051x.2000.027001030.x.

5. Magnusson I, Lindhe J, Yoneyama T, et al. Recolonization of a subgingival microbiota following scaling in deep pockets. J Clin Periodontol 1984;11(3):193-207. DOI: 10.1111/j.1600-051X.1984. tb01323.x.

6. Goodson JM, Tanner A. Antibiotic resistance of the subgingival microbiota following local tetracycline therapy. Oral Microbiol Immunol 1992;7(2):113-117. DOI: 10.1111/j.1399-302X.1992. tb00520.x.

7. Newman MG, Takei HH, Klokkevold PR, et al. Chemotherapeutic agents. Carranza's Clin Periodontol, Elsevier 2006;10:798-812.

8. Puri K, Dodwad V, Bhat K, et al. Effect of controlled release periochip on clinical and microbiological parameters in patients of chronic periodontitis. J Ind Soc Periodontol 2013;17(5):605-611. DOI: 10.4103/0972-124X.119299.

9. Kukreja BJ, Dodwad V. Herbal mouthwashes: a gift of nature. Int J Pharm Biol Sci 2012;3:46-52.

10. Silness $P$, Loe H. Periodontal disease in pregnancy. Acta Odontol Scand 1964;22(1):121-135. DOI: 10.3109/00016356408993968.
11. Loe $H$. The gingival index, the plaque index and the retention index systems. J Periodontol 1967;38(6 Part II):610-616. DOI: 10.1902/ jop.1967.38.6_part2.610.

12. Pragati $S$, Ashok $S$, Kuldeep S. Recent advances in periodontal drug delivery systems. Int J Drug Delivery 2009;1:19-23.

13. Vennila K, Elanchezhiyan S, Ilavarasu S. Efficacy of $10 \%$ whole Azadirachta indica (neem) chip as an adjunct to scaling and root planing in chronic periodontitis: a clinical and microbiological study. Ind J Dent Res 2016;27(1):15-21. DOI: 10.4103/0970-9290.179808.

14. Kaner D, Bernimoulin JP, Hopfenmuller W. Controlled delivery chlorhexidine chip versus amoxicillin/metronidazole as adjunctive antimicrobial therapy for generalized aggressive periodontitis: a randomized controlled clinical trial. J Clin Periodontol 2007;34(10):880-891. DOI: 10.1111/j.1600-051X.2007.01122.x.

15. Jurenka JS. Anti-inflammatory properties of curcumin, a major constituent of Curcuma longa: a review of preclinical and clinical research. Alt Med Review 2009;14:141-153.

16. Sharma OP. Antioxidant activity of curcumin and related compounds. Biochem Pharmacol 1976;25(15):1811-1812. DOI: 10.1016/00062952(76)90421-4.

17. Basnet $P$, Basnet NS. Curcumin: an anti-inflammatory molecule from a curry spice on the path to cancer treatment. Molecules 2011;16(6):4567-4598. DOI: 10.3390/molecules16064567.

18. Rao DVK, Singh I, Chopra PC, et al. In vitro antibacterial activity of neem oil. Ind J Med Res 1986;84:314-316.

19. Chatterjee $A$, Saluja $M$, Singh $N$, et al. To evaluate the antigingivitis and antipalque effect of an Azadirachta indica (neem) mouthrinse on plaque induced gingivitis: A double-blind, randomized, controlled trial. J Indian Soc Periodontol 2011;15:398-401. DOI: 10.4103/0972$124 X .92578$

20. Chaudhary S, Kanwar RK, Sehgal A, et al. Progress on Azadirachta indica based biopesticides in replacing synthetic toxic pesticides. Front Plant Sci 2017;8:610-617. DOI: 10.3389/fpls.2017.00610.

21. Jeffcoat MK, Bray KS, Ciancio SG, et al. Adjunctive use of a subgingival controlled-release chlorhexidine chip reduces probing depth and improves attachment level compared with scaling and root planing alone. J Periodontol 1998;69(9):989-997. DOI: 10.1902/ jop.1998.69.9.989.

22. Singh A, Sridhar R, Shrihatti R, et al. Evaluation of turmeric chip compared with chlorhexidine chip as a local drug delivery agent in the treatment of chronic periodontitis: a split mouth randomized controlled clinical trial. J Alternat Complement Med 2017;14(1):1-9. DOI: 10.1625/jcam.14.1.

23. Gottumukkala S, Sudarshan S, Satyanarayana RM. Comparative clinical evaluation of the efficacy of two controlled release devices: chlorhexidine chips and indigenous curcumin-based collagen as local drug delivery systems. Contemp Clin Dent 2014;5(2):175-181. DOI: 10.4103/0976-237X.132310.

24. Jain S, Kaur H, Brar S. To evaluate the efficacy of neem chip as an adjunct to scaling and root planing (SRP) in patients with periodontitis. Ind J Dent Sci 2012;4:42-45.

25. Mehta WP, Kudva P, Kudva PH. Comparative evaluation of the efficacy of neem and tetracycline when incorporated in a local drug delivery system when used as an adjunct to scaling and root planing a clinicomicrobiological study. IOSR J Dent Med Sci 2015;14:47-50. 